\title{
Correction to: Investigation of internal defects and premature fracture of dissimilar refill friction stir spot welds of AA5754 and AA6061
}

\author{
Antonio Cappelletti Ferreira ${ }^{1,2} \cdot$ Leonardo Contri Campanelli ${ }^{2}$. Uceu Fuad Hasan Suhuddin ${ }^{1}$. \\ Nelson Guedes de Alcântara ${ }^{2}$. Jorge Fernandez dos Santos ${ }^{1}$
}

Published online: 17 August 2020

(C) Springer-Verlag London Ltd., part of Springer Nature 2020

\section{Correction to: The International Journal of Advanced Manufacturing \\ Technology (2020) 106:3523-3531 \\ https://doi.org/10.1007/s00170-019-04819-3}

The author would like to add Acknowledgement and revise the Funding to:

Acknowledgements This study was financed in part by the Coordenação de Aperfeiçoamento de Pessoal de Nível Superior - Brasil (CAPES) Finance Code 001.

This work also gratefully acknowledges the support of Federal University of São Carlos, Graduate Program in Materials Science and Engineering, the financial support of the National Council for Scientific and Technological Development (CNPq - grant number 134522/2017-6), Brazil, and the collaboration with The Welding Institute (TWI).

Publisher's note Springer Nature remains neutral with regard to jurisdictional claims in published maps and institutional affiliations.

The online version of the original article can be found at https://doi.org/ 10.1007/s00170-019-04819-3

Antonio Cappelletti Ferreira

antonio.cappelletti@gmail.com

1 Institute of Materials Research, Materials Mechanics, Solid State Joining Processes, Helmholtz-Zentrum Geesthacht, Max-Planck-St. 1, 21502 Geesthacht, Germany

2 Department of Materials Engineering, Federal University of São Carlos, Rod. Washington Luiz km. 235, São Carlos, SP 13565-905, Brazil 